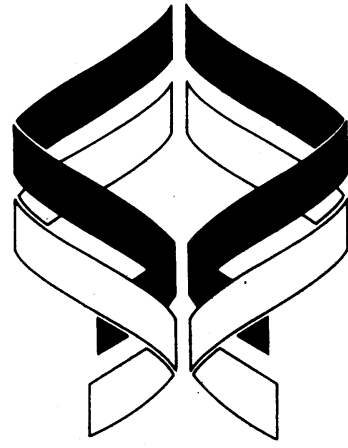

Royal Brompton and National Heart Hospital, London SW3 6HP Case presented by: A U Wells, medical registrar Chairman: K F Chung, senior lecturer in thoracic medicine

\section{Discussion group:}

T C B Stamp, consultant physician, Royal National Orthopaedic Hospital J W Studd, consultant gynaecologist, King's College Hospital

P J Barnes, professor of thoracic medicine

D M Denison, professor of clinical physiology

D N Mitchell, consultant physician

D M Geddes, consultant physician

Series edited by: Dr K F Chung.

BMF 1992;305:413-5

FIG 1-Radiograph of lumbar spine showing generalised bone demineralisation and biconcave collapse of body of $L 2$ vertebra

\section{Corticosteroid induced osteoporosis in severe menstrual asthma}

\author{
Steroid sparing drugs may be useful
}

The prevalence and severity of asthma has increased recently despite increases in drug prescriptions. Although asthma is easy to manage in most cases, many patients remain poorly controlled. ${ }^{1}$ This is especially the case in unstable or "brittle" asthma, including premenstrual asthma, ${ }^{2}$ in which lung function may fall precipitously. These patients often require very high doses of corticosteroids to prevent life threatening attacks and are at high risk of developing osteoporosis. ${ }^{3}$ Recently, attention has focused on the use of steroid sparing drugs, and methotrexate seems particularly promising in this regard. ${ }^{4}$ We present a case of difficult premenstrual asthma which highlights these issues.

\section{Case history}

A 26 year old woman with life long asthma was referred to our hospital in July 1987. She had first been admitted to hospital at the age of 14 , shortly after the onset of menstruation; she was admitted to hospital twice a year until the age of 18 when her asthma worsened, necessitating 20 admissions a year over the next five years. During the 12 months before referral she was admitted to intensive care units on seven occasions and required mechanical ventilation once. Treatment of referral consisted of fenoterol two puffs thrice daily; beclomethasone $500 \mu \mathrm{g}$ thrice daily; nebulised salbutamol as required; slow release theophylline $500 \mathrm{mg}$ twice daily; and prednisolone $15 \mathrm{mg}$ daily (her lowest maintenance dose over the past decade). Her symptoms were worse immediately before and during menstrual periods and were not suppressed by the oral contraceptive.

At transfer her peak flow recordings varied between 120 and $300 \mathrm{l} / \mathrm{min}$. On examination she was obese, cushingoid, and in mild respiratory distress. In view of the striking relation between her symptoms and menstruation, she was started on intramuscular medroxyprogesterone $600 \mathrm{mg}$ twice a week in the hope that suppression of periods might improve her asthma; treatment was otherwise unchanged. Within four weeks her peak flow recordings consistently exceeded

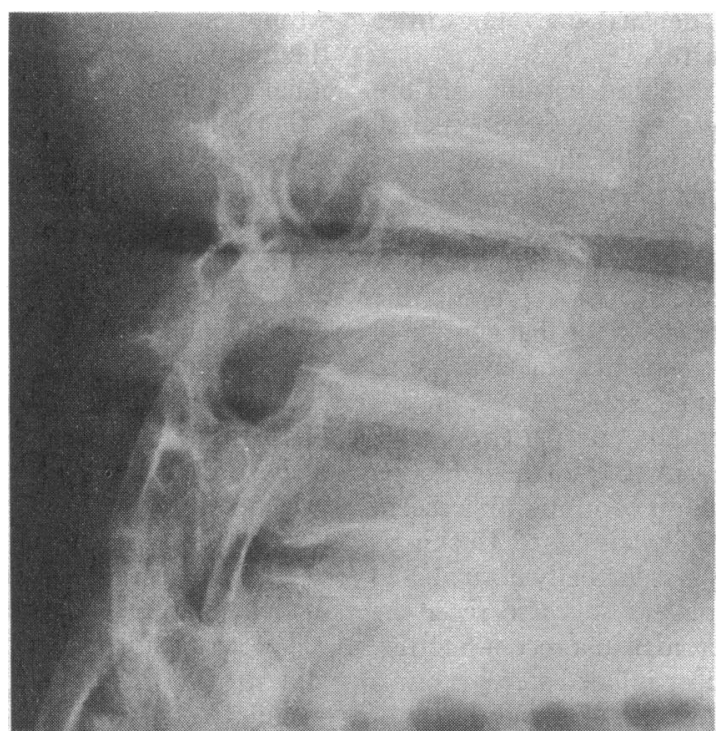

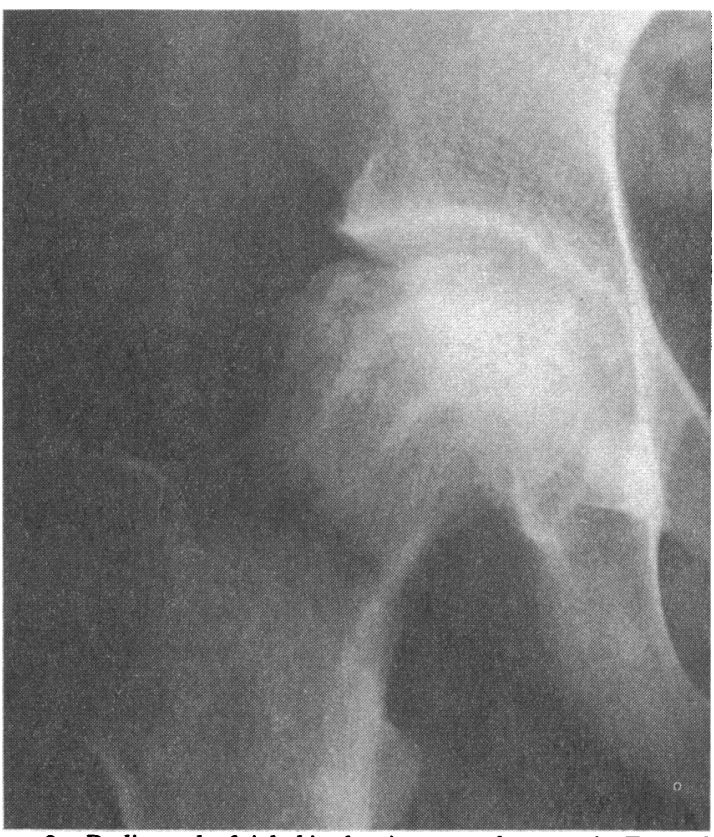

FIG 2-Radiograph of right hip showing avascular necrosis. Femoral head is sclerotic and there is flattening of articular surface with fragmentation

$300 \mathrm{l} / \mathrm{min}$, and she remained well during the ensuing year apart from one admission to hospital. However the progesterone treatment was associated with a gain of $25 \mathrm{~kg}$ and was withdrawn in July 1988 with worsening of her asthma. Despite taking azathioprine she required maintenance prednisolone $15 \mathrm{mg}$ daily and was admitted to hospital three times during the following five months. Methotrexate was started in December 1988 and resulted in a big improvement; she required no hospital admissions in 1989 and the dose of prednisolone was reduced to $5 \mathrm{mg}$ daily.

The return of her periods in December 1989 was associated with worsening asthma, necessitating three brief admissions to hospital in 1990 . However, none of these episodes was severe and the control of her symptoms was generally satisfactory. She lost her excess weight and refused further progesterone treatment.

She developed several serious side effects from prolonged corticosteroid therapy including diabetes mellitus, a severe proximal myopathy, aseptic necrosis of the left humeral and both femoral heads, and osteoporosis manifesting as bilateral cough fractures of the ribs and fracturing of the second, fourth, and fifth lumbar vertebrae (figs 1 and 2). She was briefly treated with calcitonin, but this was complicated by an allergic reaction. In October 1988 she was referred to the Royal National Orthopaedic Hospital and was started on experimental bisphosphonate treatment (pamidronate infused intravenously $15 \mathrm{mg}$ daily for eight days and thereafter 45-60 mg monthly for two years). Lumbar bone mineral density was not measured during the early months but increased by $13.9 \%$ in the second year. No further signs of osteoporosis occurred after treatment was started. She had bilateral palliative hip osteotomies.

Her treatment was stabilised at methotrexate $15 \mathrm{mg}$ 
weekly, prednisolone $5 \mathrm{mg}$ daily, slow release aminophylline $450 \mathrm{mg}$ twice daily, budesonide $800 \mu \mathrm{g}$ twice daily, and salmeterol $100 \mu \mathrm{g}$ twice daily; the addition of salmeterol had no effect on her symptoms.

\section{Comment}

Asthma is one of many medical conditions affected by the menstrual cycle. ${ }^{25}$ In premenstrual asthma symptoms usually worsen two to three days before menstrual periods and improve when menstruation begins. The mechanism is uncertain; progesterone may have immunosuppressive effects such that the premenstrual fall in progesterone concentrations allows asthma to deteriorate. Alternatively, if progesterone has similar relaxant effects on uterine and airway smooth muscle, falling progesterone concentrations may lead to rebound muscle hyperactivity.

Premenstrual asthma may be life threatening and needs to be recognised because the treatment is different from that of ordinary asthma. Oral steroids and oral progesterone are usually unhelpful. Progesterone injections are effective but may cause fluid retention and depression. Pregnancy, hysterectomy, and bilateral oophorectomy control premenstrual asthma by wiping out the menstrual cycle. Analogues of luteinising hormone releasing hormone remove the cycles pharmacologically but result in a $10 \%$ loss of bone density in a year. Subcutaneous oestrogen to stop ovulation, given by patch or implant, is often effective, even in very severe cases; however, monthly progestogen given to cause withdrawal bleeding and prevent uterine hyperplasia may be associated with worsening of asthma. In these patients hysterectomy and oophorectomy may be required.

Corticosteroids have multifactorial actions on the skeletal system. ${ }^{6}$ Cortisol first enhances, then depresses osteoblast numbers and collagen synthesis; increases the numbers of 1,25-dihydroxycholecalciferol receptors in osteoblasts; increases cyclic AMP response to parathyroid hormone within the osteoblast; depresses the concentration of bone Gla protein (osteocalcin) in the circulation; and reduces circulating concentrations of collagen peptides. Cortisol also decreases the synthesis of insulin-like growth factor 1, which mediates selective anabolic actions of parathyroid hormone. ${ }^{7}$ Finally, cortisol inhibits the production of prostaglandins, which stimulate the proliferation and differentiation of preosteoblasts. ${ }^{8}$ There are also distant effects. Cortisol stimulates release of parathyroid hormone and depresses renal tubular reabsorption of calcium and intestinal calcium absorption. With high dose corticosteroids, virtually all the excess bone mineral loss is sustained in the first year. Thereafter, the loss of bone mineral density does not differ significantly from that in controls.

Bone mineral density in the lumbar spine and hip can be measured by dual energy $x$ ray absorptiometry. Values of less than $0.9 \mathrm{~g} / \mathrm{cm}^{2}$ fall in the osteoporotic range; our patient had a lumbar bone mineral density of $0.59 \mathrm{~g} / \mathrm{cm}^{2}$ when first measured 10 months after starting pamidronate. It is common to represent bone mineral density as the $\mathrm{Z}$ score, which represents the standard deviations below the mean for that age. In 30 spontaneous crush fracture patients the average $\mathrm{Z}$ score was $1.6 \mathrm{SD}$; our patient's $\mathrm{Z}$ score was -2.96 .

Some of the improvement in our patients' bone mineral density might have resulted from the reduction in steroid dosage, and this might continue. In a recent study of 15 patients surgically cured of Cushing's disease bone mineral density was virtually normal 2-24 years later. ${ }^{9}$ However our patient was also receiving high dose inhaled corticosteroids. In a recent Scottish study patients taking high dose inhaled steroids and a separate group receiving a mean (SD) daily dose of prednisolone of $9 \cdot 6(6 \cdot 1) \mathrm{mg}$ showed respective median reductions in lumbar bone mineral density of $14 \%$ and $26 \%$ compared with a group of asthmatic patients not taking corticosteroids; these reductions were highly significant but did not differ significantly from each other. ${ }^{10}$

The bisphosphonates coat hydroxyapatite crystals and inhibit both growth and dissolution." They also affect osteoclasts; some reduce recruitment and others affect the activity of the osteoclast at the bone surface. Among the second generation bisphosphonates, pamidronate has 10 times the antiresorptive power of etidronate without any of etidronate's antimineralisation properties. ${ }^{12}$ The optimal dose and dose interval have not been established; nor is it certain whether, like other antiresorptive agents such as calcitonin and stanozolol, pamidronate increases lumbar bone mineral density during only the first one to two years of treatment, but there is evidence for prolonged continuous gain. ${ }^{1314}$

\section{Discussion}

TCBS: We have given intravenous pamidronate empirically every month for steroid osteoporosis in the hope that acute inhibition of resorption without inhibition of formation might allow new bone to be formed. In three other young adult osteoporotic patients taking high dose steroids lumbar bone mineral density improved by $7 \cdot 1 \%, 23 \cdot 5 \%$, and $37 \cdot 7 \%$ during the first 12 months of pamidronate treatment.

JWS: Steroid osteoporosis is always preventable and treatable. Postmenopausal women, anorectic patients, and those taking corticosteroids all have an increased incidence of osteoporosis ${ }^{15}$; in postmenopausal patients the increase in bone density with oestrogen replacement is directly proportional to the plasma concentration of oestrodiol achieved. Percutaneous oestrodiol escapes first pass liver metabolism and results in the correct ratio of E2 to E1 and higher levels of E2 oestradiol. On this principle, steroid osteoporosis should be treated with percutaneous implants of oestradiol $75 \mathrm{mg}$ and testosterone $100 \mathrm{mg}$ (to treat the depression and low libido associated with depressed testosterone concentrations). In steroid dependent asthmatic patients, this treatment increases spinal bone mineral density by a mean of $12 \%$ in the first year. This effect is not transient; in six patients taking steroids for 3-30 years and oestrogen for 2-20 years, bone mineral density was virtually normal. ${ }^{16}$

PJB: The possibility that inhaled steroids migh cause osteoporosis is of great concern. Even modest doses of inhaled beclomethasone can cause significant decreases in circulating osteocalcin concentrations. ${ }^{17} \mathrm{~A}$ strong case can be made for hormone replacement therapy in postmenopausal women taking high dose inhaled steroids.

DMD: Not all patients taking steroids will develop severe osteoporosis. Is there any way of identifying those at higher risk?

TCBS: In theory early changes in biochemical markers should identify these patients, but the work has yet to be done. Some patients are resistant to developing steroid induced osteoporosis.

JWS: The same question applies to postmenopausal patients; should we try to define a high risk population? $\mathrm{My}$ instinct is to offer oestrogen to all women after the menopause because osteoporosis is so common. Moreover, oestrogens have enormous cardiovascular benefits. ${ }^{18}$

DNM: Does long term oestrogen replacement result in an increased incidence of malignancy?

JWS: Probably not. The mortality from heart attacks and strokes is much reduced. Breast cancer may be diagnosed slightly more often, but three studies have 
shown that the associated mortality is decreased in this group of patients. ${ }^{19}$

KFC: What is the role of methotrexate as a steroid sparing agent?

DMG: Our recent study showed that low dose methotrexate had a substantial steroid sparing effect in a moderately large group of patients, but not in all patients. ${ }^{4}$ It should be reserved for patients with severe side effects from steroids; the side effects of long term methotrexate treatment are not fully documented.

KFC: In summary, hormonal factors seem to be important in this case. Asthma symptoms worsened after menarche and there was a close relation between symptoms and menstruation. Suppression of menstruation with progesterone improved her condition, although it resulted in depression and unacceptable weight gain. Prolonged treatment with oral corticosteroid had serious systemic side effects. Methotrexate was introduced as a steroid sparing drug to reduce the risk of further musculoskeletal complications and greatly facilitated control of her asthma; the success of this approach in our patient suggests that a trial of methotrexate may be warranted in young asthmatic patients who are steroid dependent. Monthly bisphosphonate infusions resulted in an appreciable increase in lumbar bone mineral density.

Barnes PJ, Chung KF. Difficult asthma. BMF 1989;299:695-8.

2 Beynon HLC, Garbett ND, Barnes PJ. Severe premenstrual exacerbations of asthma: effect of intramuscular progesterone. Lancet 1988;ii:370-2.

Adinoff AD, Hollister JR. Steroid-induced fractures and bone loss in patients with asthma. $N$ Engl f Med 1983;309:265-8.

4 Shiner RJ, Nunn AJ, Chung KF, Geddes DM. Randomised, double-blind, placebo-controlled trial of methotrexate in steroid-dependent asthma. Lancet 1990;336:137-40.

Magos AL, Studd J. Effects of the menstrual cycle on medical disorders. $\mathrm{Br} \mathcal{F}$ Hosp Med 1985;33:68-77.

6 Gennari C, Civitelli R. Glucocorticoid-induced osteoporosis. Clinics in Rheumatic Diseases 1986:12:637-54.

7 Canalis E, McCarthy TL, Centrella M. Production, regulation and effects of bone growth factors. In: Christiansen $\mathrm{C}$, Overgaard $\mathrm{K}$, eds. Osteoporosis 1990. Copenhagen: Osteopress ApS, 1990:243-7.

8 Raisz LG, Pilbeam CC, Klein-Nulend J, Harrison JR. Prostaglandins and bone metabolism: possible role in osteoporosis. In: Christiansen C, Overgaard K, eds. Osteoporosis 1990. Copenhagen: Osteopress ApS, 1990 253-8.

9 Manning P, Evans MC, Reid IR. Axial bone density following cure of Cushings syndrome: evidence for reversibility of steroid osteoporosis. In: Christiansen C, Overgaard K, eds. Osteoporosis 1990. Copenhagen Osteopress ApS, 1990: 1585-6.

10 Packe GE, Douglas JG, Robins SP, Reid DM. Quantitative computed tomography and indices of bone metabolism in asthma: effects of inhaled and oral corticosteroids. In: Christiansen C, Overgaard K, eds. Osteoporosis 1990. Copenhagen: Osteopress ApS, 1990:1635-6.

11 Fleisch H. Experimental basis for the clinical use of diphosphanates in Paget's disease of bone. Arthritis Rheum 1980;23:1162-71.

12 Bijvoet OLM, Frijlink WB, Jie K, van der Linden H, Meijer CJ, Mulder H, $e$ al. APD in Paget's disease of bone. Arthritis Rheum 1980;23:1193-205.

13 Valkema R, Papapoulos SE, Vismans F-J FE, Pauwels EKJ, Bijvoet OLM. A four-year continuous gain in bone mass in APD-treated osteoporosis. In: Christiansen C, Johansen JS, Ruis BJ, eds. Osteoporosis 1987. Copenhagen Christiansen C, Johansen JS,
Osteopress ApS, 1990:836-9.

14 Valkema R, Papapoulou V, Pauwels EKJ, Bijvoet OLM, Papapoulos SE. No evidence of cumulative effect of low dose APD on bone remodelling during year continuous treatment in osteoporosis. F Bone Min Res 1989;4(supp 1):370.

15 Savvas M, Treasure J, Studd J. The effect of anorexia nervosa on skin thickness, skin collagen and bone density. Br $\mathcal{F}$ Obstet Gynaecol 1989;96: 392-4.

16 Studd J, Savvas M, Johnson M. Correction of corticosteroid-induced osteoporosis by percutaneous hormone implants. Lancet 1989;i:850-1.

17 Pouw EM, Prummel MF, Oosting $\mathrm{H}$, Roos CM, Endert E. Beclomethasone inhalation decreases serum osteocalcin concentrations. BMY 1991·302:627-

18 Ross R, Paganini-Hill A, Mack T. Menopausal oestrogen therapy and protection from ischaemic heart disease. Lancet $1981 ; i: 858-61$.

19 Bergkvist L, Adami H-O, Persson I, Bergstrom R, Krusemo UB. Prognosis after breast cancer diagnosis in women exposed to oestrogen replacement therapy. Am $\mathcal{F}$ Epidemiol 1989;130:221-8.

\title{
How To Do It
}

\section{Design a clinical information system}

\author{
A P Smith
}

\section{Llandough Hospital, Llandough, South Glamorgan CF6 1XX A P Smith, consultant physician}

BMF 1992;305:415-7
When in 1989 my department decided to get a clinical information system we quickly realised that we would have to do it ourselves. Everything we looked at was much too expensive and very complicated. Three years and many man hours later our clinical information system, Dossier, is up and running. The system won the personal computer rewards competition sponsored by the Peat Marwick group and the Guardian last November. This paper describes the key points we learnt, which should be taken into account when planing a clinical information system.

Dossier is a real time, episode based, clinical information system designed around the daily work of the medical secretary. Clinical data are collected as discharge summaries and outpatient letters are typed, although on a networked system remote work stations could be used to record the presence of a patient, the secretary doing the rest while typing the discharge summary. Because our system is real time, information is immediately available to other users as it is entered, and as it is episode based and records activity as it happens it gives an accurate picture of workload.

and the ground rules are simple.

The fewer the people who enter information and the smaller the data set the more likely you are to get a full and accurate record on every case. Our data set (table) is clinically determined and omits items such as provider and purchaser codes, overseas visitor status, NHS number, place of birth, occupation of husband and father, discharge method and destination, and similar information. The choice was determined entirely by availability (who knows their NHS number?) and potential usefulness to clinicians, although we are going to have to include some of the items we originally left out because managers will need them.

When deciding on a data set, you will have to compromise between ease of data entry and demands for all sorts of information, but it is best to exclude information which is difficult to collect. Unfortunately, many recommended data sets are so inflated that no clinical department will ever be able to collect them. It should take no longer to enter a new patient and code into the computer than it takes a secretary to write the letters now, so resist unreasonable pressure to include unnecessary or awkward data items - they simply do not get filled in, or, if compulsory, slow the process of data entry to the point that it becomes irksome.

Before starting this project our knowledge of computers was limited to the usual experience of anyone doing clinical research-word processing, simple databases, medical statistics, and so on. But designing and writing this type of computer program is as much about attitudes and philosophy as technique

\section{How will data be validated?}

Consider how you will validate the contents of your database. Dossier saves the name of the person who last 